\title{
Evaluation of the Best Theoretic Approach DFT Based for Indirect Spin-Spin Coupling Constants of 3-Ishwarone
}

\author{
Eduardo da Conceição \& Mauro B. de Amorim
}

\section{Introduction}

The indirect spin-spin coupling constants (SSCC) along with chemical shifts are the most important parameters given by NMR spectroscopy. ${ }^{1}$ In this work the study focus is the calculation of indirect nuclear spin-spin coupling constants with originates in the interactions with the surrounding electrons and does not disappear in isotropic media. ${ }^{2}$

The SSCCs are very sensitive to any variation in molecular geometric structure and provides information about the arrangement and the connectivity of atoms in a molecule. ${ }^{3}$ The use of DFT based calculations are an efficient approach in the description of indirect SSCCs for various molecular models of in organic chemistry. Given at same time accuracy and lower computational costs. ${ }^{2,4}$

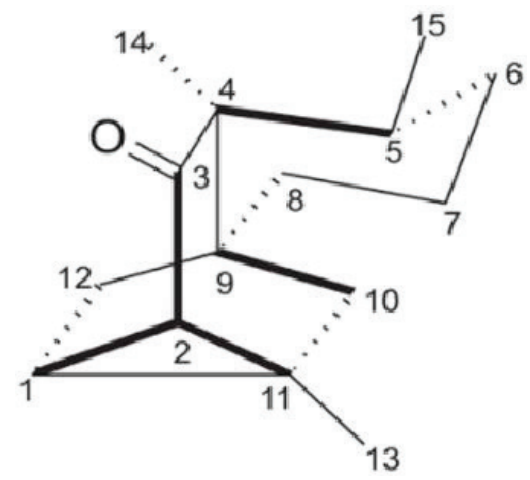

Figure 1. 3-ishwarone.

\section{Methods}

In this work we calculated the SSCCs for the molecular model of a sesquiterpene, the 3-ishwarone (Figure 1), using the Gaussian 09 package for optimization at the theoretical level B3LYP/6-31G(d,p). For the calculations of SSCCs it were used three different functionals: B3LYP, B972 and mPW1PW91 5 combined with the basis set: 6-31G, 6-31G(d,p), cc-pVTZ, cc-PCVTZ and basis sets specifically designed for coupling constants calculation: aug-cc-pVTZ-J, pcJ-2 and ccJ-pVTZ.6,7,8 The calculated results were compared with experimental data.

\section{Results and Discussion}

The results obtained in different theoretical levels demonstrated reproduce satisfactorily the experimental data, MAD and RMSD values (Figure 2) show acceptable calculated values. In the study model, the increased level of theory was not a great advantage leading to large increases in computation time without leading to significant improvements in the accuracy, like showed in other previous studies. ${ }^{9}$

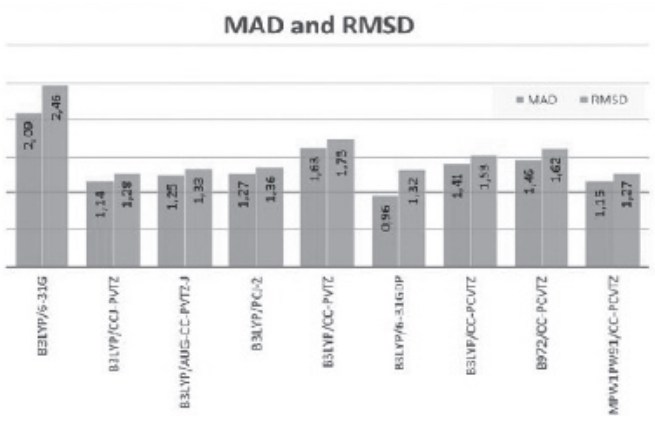

Figure 2. MAD and RMSD values. 
Calculated values of geminal couplings: ${ }^{2} \mathrm{~J}_{\mathrm{H} 10 \mathrm{aH} 10 \mathrm{~b}} \mathrm{e}$ ${ }^{2} \mathrm{~J}_{\mathrm{H} 12 \mathrm{H} 12 \mathrm{~b}}$ (Figure 3) showed similar behavior with all the different levels of theory used. The basis set cc-pCVTZ and cc-pVTZ gave lower values than the experimental values. And upper values with 6-31-G, 6-31G(d,p) and specifically designed basis sets for coupling constants calculation.

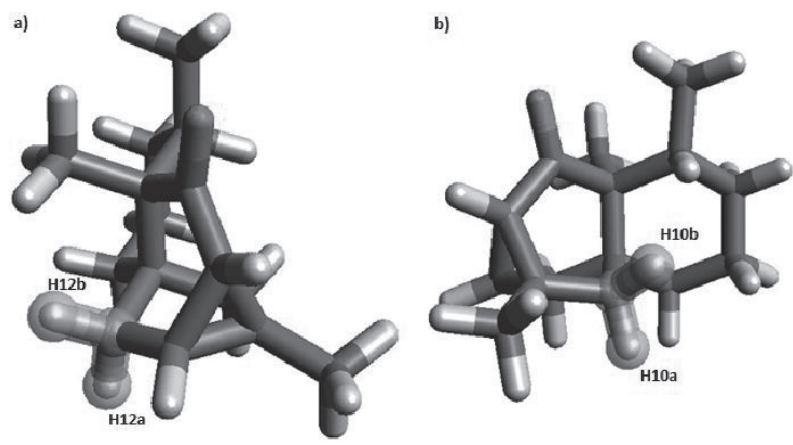

Figure 3. Geminal coupling prótons: a) ${ }^{2} \mathrm{~J}_{\mathrm{H} 12 \mathrm{aH} 12 \mathrm{~b}}$ and b) ${ }^{2} \mathrm{~J}_{\mathrm{H} 1 \mathrm{OaH} 10 \mathrm{~b}}$.

The calculated values for vicinal couplings: ${ }^{3} \mathrm{~J}_{\mathrm{H} 1 \mathrm{H} 2}$ e ${ }^{3} \mathrm{~J}_{\mathrm{H} 1 \mathrm{H} 12 \mathrm{~b}}$ (Figure 4) although underestimate the experimental values were those who had lower standard deviation.

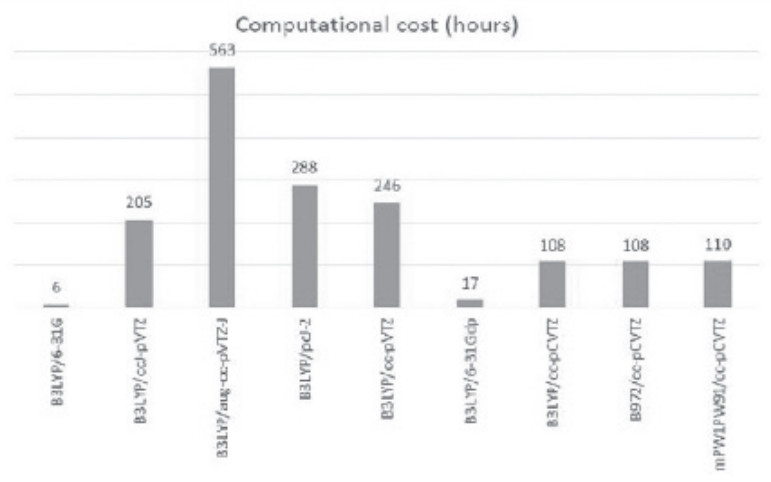

Figura 4 - Computational cost in hours.

Another important point is to know the contribution of each Ramsey's terms, which varies depending on the model under study. In the case of 3-ishwarone the fermi contact (FC) is the main contributor, suggesting that a precise determination of the $\mathrm{FC}$ is essential for reliable results. Tables 1 and 2 are shown the values of each term for vicinal $\left({ }^{3} \mathrm{~J}_{\mathrm{H} 1 \mathrm{H} 2}\right)$ and geminal $\left({ }^{2} \mathrm{~J}_{\mathrm{H} 1 \mathrm{OaH} 1 \mathrm{Ob}}\right)$ couplings.
Table 1 - Absolute values of total and separate contribuitions to indirect spin-spin coupling (in $\mathrm{Hz}$ ) for the vicinal coupling $\left({ }^{3} \mathrm{~J}_{\mathrm{H} 1 \mathrm{H} 2}\right)$.

\begin{tabular}{ccccccc}
\hline Coupling & Theory level & Total & FC & SD & PSO & DSO \\
\hline${ }^{3}$ J $_{\text {H1H2 }}$ & B3LYP/6-31G & 7,73 & 7,35 & 0,15 & 0,18 & 0,41 \\
& B3LYP/ccl-pVTZ & 8,30 & 8,10 & 0,14 & 0,33 & 0,39 \\
& B3LYP/aug-cc-pVTZ-J & 8,41 & 8,22 & 0,14 & 0,35 & 0,39 \\
& B3LYP/pcl-2 & 8,30 & 8,12 & 0,15 & 0,35 & 0,39 \\
B3LYP/cc-pVTZ & 6,70 & 6,40 & 0,15 & 0,26 & 0,41 \\
B3LYP/6-31Gdp & 7,31 & 6,96 & 0,14 & 0,19 & 0,40 \\
B3LYP/cc-pCVTZ & 8,81 & 8,41 & 0,18 & 0,60 & 0,82 \\
& B972/cc-pCVTZ & 8,06 & 7,67 & 0,17 & 0,61 & 0,83 \\
mPW1PW91/cc-pCVTZ & 8,80 & 8,39 & 0,18 & 0,61 & 0,83
\end{tabular}

Table 2 - Absolute values of total and separate contribuitions to indirect spin-spin coupling (in Hz) for the geminal coupling $\left({ }^{2} \mathrm{~J}_{\mathrm{H} 1 \mathrm{OaH} 10 \mathrm{~b}}\right)$.

\begin{tabular}{ccccccc}
\hline Coupling & Theory level & Total & FC & SD & PSO & DSO \\
\hline${ }^{2} J_{\text {H10aH10b }}$ & B3LYP/6-31G & 16,20 & 16,30 & 0,52 & 0,39 & 0,81 \\
& B3LYP/ccl-pVTZ & 12,96 & 13,73 & 0,44 & 1,33 & 1,01 \\
& B3LYP/aug-cc-pVTZ-J & 13,31 & 13,96 & 0,41 & 1,23 & 0,99 \\
& B3LYP/pcl-2 & 13,46 & 14,22 & 0,41 & 1,35 & 1,01 \\
B3LYP/cc-pVTZ & 10,59 & 11,20 & 0,41 & 1,21 & 1,01 \\
B3LYP/6-31Gdp & 13,17 & 13,51 & 0,32 & 0,97 & 0,96 \\
B3LYP/cc-pCVTZ & 10,65 & 11,29 & 0,39 & 1,00 & 0,75 \\
B972/cc-pCVTZ & 10,64 & 11,27 & 0,39 & 0,98 & 0,73 \\
mPW1PW91/cc-pCVT2 & 11,56 & 12,21 & 0,41 & 0,96 & 0,71
\end{tabular}

\section{Acknowledgments}

The authors are grateful for the support given from the CAPES.

\section{References}

1. J. San Fabían, J. M. García de la Vega, E. San Fabían, J. Chem. Theory Comput. 10, 4938-4949, (2014).

2. T. Helgaker et al. Prog. in NMR Spec., 53, 249- 268 (2008).

3. L. J. Smith. J. Mol. Biol., 255, 494-506 (1996)

4. R. Rittner et al. Chem. Phys. Let., 454, 129-132 (2008).

5. T. Kupka et al. J. Phys. Chem. A, 116, 3728- 3738 (2012).

6. S. P. A. Sauer et al. Theor. Chem. Acc. 100, 275- 284 (1998).

7. F. Jensen. Theor. Chem. Acc. 126, 371 (2009).

8. U. Benedikt, A. A. Auer, F. Jensen. J. Chem. Phys. 129, 064111 (2008).

9. M. Alipour. RSC Adv. 5, 4737-4746 (2015).

\section{Eduardo da Conceição ${ }^{a, *}$ \& Mauro Barbosa de Âmorim ${ }^{b}$}

a, bWalter Mors institute of Research on Natural Products (IPPN), Federal University of Rio de Janeiro (UFRJ)

"E-mail: eduardodcon@gmail.com 